\title{
Desejando a diferença: considerações acerca das relações entre os terapeutas ocupacionais e as populações tradicionalmente atendidas por estes profissionais*
}

\begin{abstract}
About the desire for difference: considerations concerning the relation between occupational therapists and the population traditionally assisted by them
\end{abstract}

\author{
Elizabeth M. F. Araújo Lima ${ }^{(1)}$
}

\begin{abstract}
LIMA, E. M. F. A. Desejando a diferença: considerações acerca das relações entre os terapeutas ocupacionais e as populações tradicionalmente atendidas por estes profissionais. Rev. Ter. Ocup. Univ. São Paulo, v. 14, n. 2, p. 64-71, maio/ago. 2003.

RESUMO: Este artigo parte da premissa de que é o compromisso ético-político do terapeuta ocupacional com a população alvo da atenção em terapia ocupacional que cria uma nova direção para as práticas neste campo. Neste sentido se propõe a pensar esta população, tentando construir um olhar que a transversalize em busca de devires inusitados, transitando das populações e dos processos de exclusão para os processos de singularização e a produção de diferentes formas de vida.
\end{abstract}

DESCRITORES: Terapia ocupacional/tendências. Socialização. Isolamento social.

\footnotetext{
Este artigo é fruto de pesquisas preliminares para o desenvolvimento da tese de doutorado "Das obras aos procedimentos: ressonâncias entre os campos da Terapia Ocupacional e da Arte", apresentada ao Programa de Estudos Pós-Graduados em Psicologia Clínica da PUC/SP em junho de 2003.

(1) Docente do Curso de Terapia Ocupacional do Departamento de Fisioterapia, Fonoaudiologia e Terapia Ocupacional da FMUSP. Mestre pelo Programa de Estudos Pós-Graduados em Psicologia Clínica da PUC-SP. Doutora em Psicologia Clínica pelo mesmo Programa.

Endereço para correspondência: Rua Ministro Américo Marco Antônio, 351. CEP: 05442-040. São Paulo, SP. e-mail: elizabeth.lima@uol.com.br
} 


\section{INTRODUÇÃO}

A Terapia Ocupacional é um campo de práticas e saberes constituído historicamente para responder a problemáticas relacionadas a populações que, por razões diversas, sofreram a ação de processos de exclusão. Para Soares (1991, p. 139), a Terapia Ocupacional surgiu basicamente de dois processos: de um lado a ocupação dos doentes crônicos em hospitais de longa permanência, com base em programas laborterápicos; de outro, ações que visavam a restauração da capacidade funcional dos incapacitados físicos em programas de reabilitação. Nos dois casos o princípio da ocupação estava na manutenção ou recuperação da capacidade produtiva e no exercício para o trabalho. Nesta perspectiva, a Terapia Ocupacional seria, em sua origem, um domínio no campo das ações disciplinares cuja prática estaria vinculada à docilização dos corpos, modelando-os e preparando-os para fazer parte do mundo do trabalho capitalista e adentrar o exército industrial de reserva.

No entanto, algumas formas de se fazer terapia ocupacional têm, no contemporâneo, invertido a lógica disciplinar e produzido caminhos que apontam para a direção oposta, afirmando o direito à diferença e encontrando positividade em formas de vida, as mais singulares e em situações, as mais adversas. O pivô dessa inversão das práticas e suas lógicas tem sido, ao meu ver, o compromisso ético-político que os terapeutas ocupacionais têm assumido com a população alvo de suas ações. Compromisso este surgido, talvez, de uma estranha proximidade, uma zona de indiscernibilidade que se instaura entre o terapeuta ocupacional e seu paciente, decorrente do lugar - de certa forma marginal - que a Terapia Ocupacional tem ocupado frente à Medicina e a Psiquiatria. Neste sentido, podemos pensar na Terapia Ocupacional como uma disciplina menor no campo das ações disciplinares - tomando a noção de literatura menor desenvolvida por Deleuze e Guattari (1977, p. 25), o que possibilitaria a seus técnicos tomar a língua médico-psiquiátrica modificando-a por um forte coeficiente de desterritorialização, produzindo solidariedade numa comunidade frágil e criando condições para a expressão de uma outra sensibilidade e de outras formas de se produzir práticas e conhecimentos.

Então se é o compromisso ético-político com a população alvo da atenção em terapia ocupacional que cria uma nova direção para as práticas, vamos explorar mais de perto essa população, tentando construir um olhar que a transversalize em busca de devires inusitados, transitando das populações para os processos de singularização.

\section{Anormalidades}

Sabemos, a partir de Foucault (1982, p. 131), que a produção de populações como alvo de práticas clínicas e terapêuticas é uma produção histórica que faz parte de um progressivo desenvolvimento do poder sobre a vida, associado a um poder de normalização dos processos vitais, que se dá a partir do século XVII. Esse desenvolvimento se deu em duas formas principais: a primeira centrada no corpo e seu adestramento, na ampliação de suas aptidões, no investimento em sua docilidade e utilidade e na extorsão de suas forças, através do que Foucault (2001) chamou de disciplinas, caracterizadas por uma anátomo-política do corpo. As disciplinas constituem dispositivos com finalidade de operar efeitos de normalização (p. 31).

A segunda forma de poder sobre a vida, que se formou em meados do século XVIII, centrou-se no corpo-espécie, como suporte dos processos biológicos, caracterizado pela dinâmica do vivo. A essa forma de exercício do poder, que Foucault chamou de biopolítica da população, interessa conhecer, regular e controlar os nascimentos, a mortalidade, o nível de saúde, a duração da vida de determinadas populações e todas as condições que podem fazer esses processos variarem. A partir da instauração dessa biopolítica vemos surgir um mecanismo, que se quer permanente, de vigilância e controle, e a organização de populações divididas em grupos com características peculiares tomadas como traço identitário. Entre elas, a produção dos anormais que Foucault acompanhou em seu Curso de 1974-1975, no Collège de France.

Foucault (2001, p. 69) diz que a personagem do anormal surge no cruzamento entre três figuras da anomalia: o monstro humano; o indivíduo a ser corrigido - ou, em todo caso, aquele que não é assimilável ao sistema normativo de educação; e a criança masturbadora. Faz surgir, assim, nesta personagem, a composição de traços daquilo que fica no limite do humano e é o modelo de todas as pequenas discrepâncias e desvios contra a natureza; traços da delinquiência e dos desvios em relação à lei; e traços da sexualidade perversa e mal direcionada, que articula o desvio da natureza ao desvio social.

Sobre esta personagem anormal, que serve como pano de fundo para a construção de uma idéia de normalidade humana, o poder vai se exercer através de práticas e políticas em relação ao desvio, articuladas a duas modalidades de controle, diretamente relacionadas 
LIMA, E. M. F. A. Desejando a diferença: considerações acerca das relações entre os terapeutas ocupacionais e as populações.

às duas formas de poder às quais nos referimos acima. Para falar da primeira modalidade de controle, o autor utiliza como exemplo e modelo a exclusão dos leprosos e diz que se caracteriza por uma prática de rejeição e marginalização dos indivíduos, que são assim expulsos da cidade e impedidos de circulação social. Mas, nos diz ele, há uma outra modalidade de controle que parece ser uma forma maior e mais duradoura, cujo modelo é o da peste. Esta modalidade se concretiza no policiamento da cidade e diz respeito ao controle dos indivíduos através de uma forma de inclusão constituída pela análise pormenorizada do território e de seus elementos e pelo exercício de um poder contínuo.

Não se trata de uma exclusão, trata-se de uma quarentena. Não se trata de expulsar, trata-se ao contrário de estabelecer, de fixar, de atribuir um lugar, de definir presenças, e presenças controladas. Não rejeição, mas inclusão. (...) Trata-se de uma série de diferenças sutis, e constantemente observadas, entre os indivíduos que estão doentes e os que não estão (FOUCAULT, 2001, p. 57).

No Brasil, entre as anormalidades, a vadiagem ganha, já desde o séc. XVIII, um lugar de destaque. O vadio é percebido como perigoso, vive no mato, separado das trocas humanas, gente-fera, misto de homem e animal. Sendo este um problema que se colocada de forma incisiva para a época, emergem propostas para seu enfrentamento visando a organização dos vadios, então dispersos, através da criação de uma população que deveria ser recolhida em casas de correção onde aprenderia um ofício. Este é um entre outros projetos que visam homogeneizar os habitantes, ordenar uma população que é caótica, revoltosa, mole, frouxa e, sobretudo doente. "A doença acompanha a pobreza, o ócio, o vício e o crime, características de cidades sem trabalho, entregues ao luxo ilusório que a escravidão possibilita" (MACHADO et al., 1978, p. 115).

Neste contexto, a imoralidade é causa de doença e consequiência de uma vida sedentária, do ócio e da riqueza adquirida sem trabalho. A escravidão começa a ser vista como origem de todos os males que se encarnam no corpo do negro; aquele que é em princípio vítima maior desse sistema escravocrata é visto como portador de um perigo a ser evitado.

É deste pano de fundo que nasce, no século XIX no Brasil, um novo tipo de medicina, a medicina social que, tomando a sociedade em sua desorganização e mau funcionamento como causa de doenças, deve intervir em todos os campos para neutralizar todo perigo possível, o que só pode ser feito através de uma prevenção e de um controle cada vez mais acirrados
(MACHADO et al., 1978, p. 248).

Este objetivo de realizar uma sociedade sadia conecta a medicina social, desde sua origem ao projeto de transformação do desviante em um ser normalizado, e para isso é preciso patologizar esse desvio e criar tecnologias capazes de "curá-lo", visando a normalização da sociedade como um todo. É assim que, no bojo da medicina social, nasce no Brasil, a psiquiatria que será o campo de saberes e práticas que se debruçará sobre a diferença e o sofrimento psíquico, transformando-os em estados patológicos ou anormais e, ao, mesmo tempo, propondo procedimentos terapêuticos visando re-estabelecer a normalidade, entre eles a cura através de um trabalho organizado e bem orientado. A incidência desta prática se dá no campo social e em cada um dos indivíduos, que são, em última análise, produto desta relação normalizadora que será estabelecida entre a cidade e a população (MACHADO et al., 1978, p. 281).

O efeito de normalização atravessa toda a população, instaurando a tendência a categorizar e classificar cada uma das pequenas fragilidades que venham em algum momento tomar o corpo e se fazer presente na vida cotidiana, de forma a se construir uma certa gradação entre normal e anormal.

Será em toda parte, o tempo todo, até nas condutas mais ínfimas, mais comuns, mais cotidianas, no objeto mais familiar, que a psiquiatria encarará algo que terá, de um lado, estatuto de irregularidade em relação a uma norma e que deverá ter ao mesmo tempo estatuto de disfunção patológica em relação ao normal (FOUCAULT, 2001, p. 205).

Estamos, ainda hoje, e talvez mais do que nunca, atravessados por essa lógica biopolítica, tal como descrita por Foucault.

Quando fragilidades criam anomalias ou diferenciações que se conectam de alguma forma com a lógica e as forças do mercado, podem ser molarizadas e tomadas como identidades-moldes. Assim, agrupamse na mesma categoria uma série de experiências que podem vir a servir para que outros (às vezes informes ou em processos de perda ou mudança de forma) nelas venham se modelar ou encontrar uma forma aceita e valorizada. A Revista da Folha nos presenteia semanalmente com novas categorias: "as meninas Sandy", "os moderninhos", "os yetties pós-yupies", “os neo-hippies". Para cada um deles, uma forma de vestir, de andar, de falar, os lugares a freqüentar, os amigos que ter.

Há outras anomalias que podem se conectar com o mercado "da saúde" (ou seria melhor dizer, da doença), seja pela via da farmacologia ou da infinidade 
de serviços de cuidados terapêuticos. Essas são organizadas em síndromes; a cada dia uma nova nos é apresentada com seus sintomas e suas curas. Cada um de nós poderia reconhecer nos quadros de sintomas de tantas síndromes, atos, ritos, comportamentos que em algum momento nos compõem. Foucault (2001) nos diz que o movimento de consolidação de excentricidades em síndromes se faz presente desde o final do século XIX, introduzindo no domínio da psiquiatria

toda uma gente que é para ela, nesse momento, totalmente nova: a população dessas pessoas que não apresentam sintomas de uma doença, mas síndromes em si mesmas anormais, excentricidades consolidadas em anomalias (p. 395).

E há ainda aquelas anomalias que nos colocam no limite do que somos, ou do que queremos crer que somos, que recusam ou mesmo põem a baixo uma construção imaginária ideal de homem e da humanidade. Anomalias tomadas por anormalidades. Essas, mais que quaisquer outras, ficam congeladas, aprisionando a existência em estados nos quais se inventariam as formas em termos de falta: falta de cuidado, falta de casa, falta de razão, falta de família, falta de habilidade, falta de inteligência, falta de saúde, falta de instrução..., o que desemboca numa visão homogênea de miséria, abandono, diferença. Produz-se, assim, um desvalor que se faz acompanhar de processos de marginalização nos quais pessoas-margens são cada vez mais vigiadas, controladas e segregadas em relações que expõem a face cruel do nosso modo de vida.

Em todos essas situações diferenças moleculares e singularidades em processo são tomadas como dados; uma marca é tomada pelo todo. Cria-se, de um processo de diferenciação, uma diferença identitária ou molar que possibilita agrupar numa mesma gaveta todos aqueles que portam aquele traço - apenas um traço entre tantos que compõem uma existência, homogeneizando-o e despotencializando-o.

Opera-se assim uma homogeneização e segregação de intensidades heterogêneas, rebatendo-as sobre um plano único. Passa-se da singularidade de cada uma das infinitas maneiras de existir para um só e mesmo quadro de referências identificável. Criam-se barreiras, segmetariedades, enclausuramentos identitários. Qualquer tentativa de salto para a exterioridade desencadeia uma nova codificação que traz agregado um valor: enquanto algumas dessas identidades vêm acompanhadas de uma valorização de acordo com seu valor de mercado, outras são acopladas, grudadas ao desvalor que enfraquece aquelas vidas.
Esses processos encarnam-se em formas terminais como as prisões, os asilos, as diversas instituições totais.

É essa maneira de captar os processos de singularização e enquadrá-los imediatamente em referências teóricas por parte de especialistas, referências de equipamentos coletivos e segregadores (GUATTARI; ROLNIK, 1986, p. 78).

Assim, as duas formas de poder sobre a vida descritas por Foucault, se articulam à produção de saber em diferentes domínios disciplinares que vão desenvolver estratégias e se ocupar de determinadas parcelas da população como alvo de suas práticas. Entre eles está a Terapia Ocupacional, domínio particular da proteção social, cuja prática está fortemente marcada pelo contato privilegiado com as diversas anomalias, em seu formigamento constante e cotidiano.

Os terapeutas ocupacionais estão, assim, colocados nesse jogo de forças, imbuídos de um mandato social de controle e submetidos a este mesmo controle. Mas muitos estão também atravessados por um desejo de emancipação de sua prática que só pode se dar em conexão com a emancipação das pessoas que são objetos dessa mesma prática. Franco Basaglia já nos alertava que a exclusão e o aprisionamento dos doentes mentais nos asilos era também a exclusão e o aprisionamento dos técnicos do saber prático designados para cuidar deles (BASAGLIA, 1985, p. 103).

Já desde as décadas de 70 e 80, muitos terapeutas ocupacionais têm integrado um movimento de questionamento do papel dos técnicos da saúde, desvelando "as condições em que se encontram seus pacientes e o espaço de contradição que ocupam entre uma função terapêutica de um lado e uma função de controle social do outro" (BRUNELLO et al., 2001, p. 44). A partir desse questionamento sua ação se dirigiu para a construção de possibilidades de vida para seus pacientes. E se a exclusão e o desvalor que estão colados a esses sujeitos grudam-se também aos profissionais que deles se ocupam, o enriquecimento que pode ganhar lugar neste processo diz respeito à vida de todos os envolvidos.

Assim, tendo acompanhado a constituição histórica de grupos populacionais que são alvo de práticas disciplinares, nos voltamos agora para a tentativa de pensar esses grupos, não de modo a categorizá-los, mas buscando encontrar traços e linhas que os atravessam e que possam ser acompanhados e percorridos na construção de formas de resistências diante dos processos de exclusão. 


\section{Um enfoque transversal: desfiliação e precariedade}

No texto Da indigência, à exclusão, à desfiliação, Robert Castel se propõe a pensar uma longa lista de situações que demandam formas diferenciadas de intervenção social:

Indigentes, deficientes, mendigos, vagabundos, velhos, doentes sem recursos, crianças sem pais, camponeses sem terra, cidadãos sem domicílio, operário sem emprego, abandonados por conta do crescimento e regidos pela civilização, marginais de toda espécie... (CASTEL, 1994, p. 21).

Seu objetivo não é tomar essas diversas situações de forma a categorizar ou caracterizar clientelas novas e apreciar as diferenças entre elas, mas buscar um enfoque transversal e compreensivo em relação à definição desses grupos, para pensar uma situação recente na França: a constituição de grandes grupos humanos excluídos dos processos sociais.

Para compreender esse cenário o autor retoma a constituição das políticas sociais na França no Antigo Regime e encontra ali uma linha dura que divide as populações desprovidas: aquela que distingue os aptos dos inaptos para o trabalho. Esses últimos seriam os inválidos de todo tipo: alguma deficiência, doença ou a idade avançada tornou a pessoa incapaz de prover sua auto-subsistência, o que suscita por parte da sociedade a constituição de práticas e instituições de assistência. Totalmente diferente é, neste contexto, o tratamento dado ao indigente apto ao trabalho, ao qual é exigido que trabalhe. Esta problematização, que emerge de forma clara em meados do século XIV, se manterá durante cinco séculos sem que seja questionada a divisão entre a indigência daqueles que podem trabalhar e a miséria dos que são inaptos ao trabalho (CASTEL, 1994, p. 26).

A este primeiro critério, de posição em relação ao trabalho, um outro se somará: o da proximidade social. Somente aquele indigente reconhecido como integrante de uma dada comunidade será segurado. $\mathrm{O}$ autor encontra, então, um duplo processo constituindo "esses seres de carne e osso, de sangue e sofrimento (...): aquele que vai da integração à exclusão na ordem do trabalho e aquele que vai da inserção ao isolamento na ordem sóciorelacional"'(CASTEL, 1994, p. 28).

A partir desta constatação, o autor se propõe a pensar as situações de privação como um efeito da conjunção desses dois vetores - o do trabalho / nãotrabalho e o da inserção / não-inserção em uma rede relacional - e, cruzando-os, constrói um esquema no qual são definidas quatro zonas de existência social: a zona de integração, a zona de vulnerabilidade, a zona de assistência e a zona de desfiliação. Nesta última zona estariam aqueles grupos marcados por um modo particular de dissociação do vínculo social que o autor denomina de desfiliação. Sem subestimar a dimensão econômica, o autor chama nossa atenção para o fato de que determinadas populações requerem e mobilizam intervenções sociais não apenas pela situação de pobreza em que se encontram, mas pela fragilidade de seu tecido relacional.

Em seguida, nos mostra que este esquema é passível de nos ajudar a compreender a cena contemporânea, na qual novas figuras da inseguridade emergem, revelando a marca de uma dupla precariedade: a da organização do trabalho e a da estruturação da sociabilidade ou redes sociais. Neste contexto - com o esfacelamento do Estado Providência, a explosão do desemprego, a desestruturação do mercado de trabalho, o empobrecimento da estrutura familiar enquanto vetor de inserção relacional e o retraimento das redes de solidariedade -, a pobreza sobrevive, mas a ela somasse um quadro no qual a zona de vulnerabilidade está em expansão e passa a alimentar continuamente a zona de desfiliação.

Para finalizar, Castel (1994, p. 48) afirma que se propôs a pensar a partir dos conceitos de precariedade, vulnerabilidade e desfiliação, ao invés de marginalidade ou desvio, para marcar uma diferença para ele fundamental: aqui se está diante de processos e não de estados. A partir de uma perspectiva dinâmica, diz ele, é possível se dar conta desses processos "antes que a instabilidade das situações se congele em destino".

Vemos que o conceito de precariedade - que surgiu na sociologia associado a condições econômicas e sociais e definido como "ausência de uma ou mais formas de seguridade social, em especial aquela do emprego que permite às famílias e às pessoas assumirem suas obrigações profissionais, familiares e sociais e gozarem de seus direitos fundamentais." Bonnet (2000, p. 1), teve seu sentido ampliado para abarcar a fragilidade de redes relacionais e de suporte que, associada à exclusão do mercado de trabalho, desemboca em privação e isolamento.

Um outro autor, Lazarus (2000, p. 6), propõe ainda uma outra ampliação do termo que compreenda uma posição diante do mundo marcada por vivências ligadas a um tempo de efemeridade, de fragilidade, de incerteza, de ansiedade e insegurança. Para além das faltas objetivas dos seguros básicos que possibilitariam a organização de uma vida cotidiana mais ou menos estável, a precariedade seria também, nesta perspectiva, um impacto sobre o imaginário individual e coletivo. Neste quadro, a precariedade não concerniria somente aos mais excluídos; nós nos situaríamos todos em relação a um imaginário de precariedade, que, associado à errância, dá o tom da vida em nossos dias (LAZARUS, 2000, p. 10). 


\section{Outras linhas transversais: singularidade e devir-minoritário}

Assim, se do ponto de vista macro-político a precariedade material e relacional se estende cada vez para um contingente maior de pessoas, para além dela, uma outra precariedade - esta relacionada aos modos de subjetivação e a constituição de subjetividades sempre em estado de inacabamento, parece pouco a pouco deixar de ser tomada como propriedade ou característica de alguns poucos sujeitos para atravessar todo o campo social atual.

Nesta perspectiva, incompletude ou inacabamento começam a ser vistos como constitutivos do modo como existimos - corpos radicalmente abertos e incompletos, longes do equilíbrio, "marcados pela auto-organização que combina, descombina e recombina a ordem, a desordem, a reorganização" (CARVALHO, 1998, p. 12).

Se, por um lado, isto faz com que corramos o risco de sermos todos, em algum momento, diagnósticados e colocados em alguma categoria homogeneizadora - e devemos levar em conta que hoje as formas terminais de segregação estão cada vez mais diluídas e disfarçadas nas relações sociais mais cotidianas, por outro, essa constituição precária e inacabada de nossa tessitura, poderia abrir a possibilidade de seguir um devir e encaminhar nossa existência para um outro lugar ainda não experimentado. Poderia, enfim, abrir a possibilidade de criação de novas configurações para nós mesmos e para o mundo.

Pois mesmo que sejamos habituados a ver, com nossos olhos viciados, em alguém, um inválido, em outro, um desabilitado, em vários outros, incapazes de todo tipo, pessoas às quais sempre falta algo, que se configuram como oposições ao modo humano normal de ser, algo nos inquieta e nos faz desconfiar dessa negação maciça da experiência singular. Aprendemos com Deleuze a sempre desconfiar quando nos deparamos com limitações ou oposições e procurar aquilo que elas recobrem: "um formigar de diferenças, um pluralismo de diferenças livres, selvagens ou não domesticadas, um espaço e um tempo propriamente diferenciais, que persistem através de simplificações do limite ou da oposição" (GIL, 2000, p. 72).

Estamos em meio a uma guerra entre a proliferação de diferenças, como a nos dizer que há infinitas formas de ser, e a crescente e poderosíssima força de homogeneização que tenta estabelecer as bases de um modo de existência único. Movimentos em direções opostas que estão absolutamente entrelaçados no contemporâneo.

Muitas vezes as forças homogeneizadoras tomam os processos de diferenciação reduzindo-os a mera produção de variedades.

Há sempre algo de precário, de frágil nos processos de singularização. Eles estão sempre correndo o risco de serem recuperados, tanto por uma institucionalização, quanto por um devir grupelho (GUATTARI; ROLNIK, 1986, p. 53).

Outras vezes, são as forças heterogenéticas que se apossam de movimentos homogeneizadores, provocando ou desdobrando neles as mais inesperadas linhas de fugas. Como quando desses aprisionamentos identitários se percorre um caminho para migrar de uma situação segregativa para um devir minoritário, através de processos de minorização que abrem espaço para diferentes processos de singularização.

Esses processos de singularização têm como traço comum "um devir diferencial que se sente por um calor nas relações, por uma afirmação positiva da criatividade" (GUATTARI; ROLNIK,1986, p. 47). São compostos por minúsculos e sutis movimentos, esboços de diferenças que fazem diferenças, singularidades, enfim, entendidas aqui como situações-limite na qual as coisas funcionam de modo anômalo (PAOLA, 1999). Singularidades que são constantemente espantadas, mas que, se acolhidas, podem desembocar num caminho no qual uma pessoa-margem venha a sair de uma situação de marginalidade para seguir um devir-minoritário.

A distinção que Guattari e Rolnik (1986) fazem entre essas duas posições pode nos ajudar. Pessoas-margens - nos dizem eles -,

\begin{abstract}
...são vítimas de uma segregação e são cada vez mais controladas, vigiadas, assistidas (ao menos nas sociedades desenvolvidas) (...) tudo o que não entra nas normas dominantes é enquadrado, classificado em pequenas prateleiras, em espaços particulares. (...) As minorias são outra coisa (...) elas reivindicam a não participação no modo de valores, de expressão da maioria (GUATTARI; ROLNIK, 1986, p. 122).
\end{abstract}

Há ainda ocasiões em que as próprias minorias produzem para si uma identidade minoritária em torno da qual se organizam e a partir da qual desenvolvem sua luta.

Lazzarato (1998, p. 58), acompanhando o pensamento de Deleuze e Guattari, entende que uma minoria é sempre um devir em processo, e diz que quando uma minoria cria modelos é por que isso se faz necessário para sua sobrevivência, para ser reconhecida e defender seus direitos. Para ele, as lutas das minorias propõem relações inéditas com o estado e com as instituições e novas formas de subjetivação, mesmo quando exercidas a partir de uma organização de base identitária, criada em 
torno a um traço que converte um conjunto aleatório de pessoas em grupo com necessidades semelhantes.

Essas lutas possuem, assim, uma dupla direção: rechaçam o modelo majoritário, produzindo novas relações sociais, novas formas de vida, novas sensibilidades, mas ao mesmo tempo, muitas vezes afirmam uma identidade ainda que minoritária. Segundo este autor a estratégia que consiste em assumir uma identidade para superá-la depois em processos de subjetivação imprevisíveis, é uma característica comum a todas as lutas minoritárias. A questão que se coloca é de que forma assumir uma identidade como território existencial, sem deixar-se aprisionar em uma nova classificação; como fazer com que essas lutas de minoria não busquem só a transformação da situação de um determinado grupo, mas sejam condição para o rompimento com a subordinação da potência produtiva do sócius e afirmem o desejo de diferença.

\section{CONCLUSÃO}

Hoje a atenção em terapia ocupacional não se volta somente para pessoas cujas vidas estão marcadas por processos de exclusão, mas o vínculo com essas populações deixou um traço distintivo neste campo de práticas e saberes.

Trabalhando no sentido da "emancipação e autonomia de pessoas que, por razões ligadas a problemáticas específicas (físicas, sensoriais, psicológicas, mentais e/ou sociais), apresentem, temporária ou definitivamente, dificuldades na inserção e participação na vida social" (site do CURSO DE TERAPIA OCUPACIONAL DA USP), os terapeutas ocupacionais estão sempre lidando com as desvantagens sociais impostas a sujeitos ou grupos, decorrentes de uma diferença presente em suas existências.

No caminho para desfazer ou minimizar essas desvantagens e abrir espaços de sociabilidade, de expressão da diversidade e de enriquecimento das vidas desses sujeitos e grupos, o terapeuta ocupacional engrossa o movimento de luta por cidadania, na construção e na defesa dos direitos substanciais de seus pacientes (BRUNELLO et al., 2001, p. 45).

Mas, este compromisso ético-político dos terapeutas ocupacional com os sujeitos que atende pode fazer surgir, para além da tolerância e da defesa dos direitos, o desejo de diferença. Para Félix Guattari (1996, p. 216), a questão de aceitação da alteridade não é somente uma questão de tolerância diante de um outro grupo, não é só uma questão de direito, mas é fundamentalmente uma questão de desejo. E desejar o dissenso, a alteridade, a diferença só é possível quando assumimos a multiplicidade que nos compõe.
No embate entre as forças de homogeneização e controle das diferenças e aquelas heterogenéticas, isto é, produtoras de diferenças, este desejo nos engaja na busca de abrir possibilidades para que experimentemos, todos, os caminhos que levam de uma identidade minoritária a um devir-minoritário, atuando no enfrentamento dos processos de homogeneização das diferenças que desembocam em exclusão e tentando abrir espaço para que essas diferenças se re-conectem a movimentos de singularização.

Para isso seria necessário, segundo Negri (2001), cavar sempre

\begin{abstract}
...a partir do ponto mais baixo: esse ponto não é a prisão enquanto tal, é simplesmente onde as pessoas sofrem, onde elas são as mais pobres e as mais exploradas; onde as linguagens e os sentidos estão mais separados de qualquer poder de ação e onde, no entanto, ele existe; pois tudo isso é a vida e não a morte (p. 55).
\end{abstract}

Talvez entrando em conexão com este ponto onde as pessoas sofrem, possamos encontrar uma força subjetiva coletiva, da qual nos fala Negri (2001), capaz de resistência diante de um "modelo universal exclusivo que tem por característica primeira excluir massas inteiras de uma pretensa universalidade inclusiva" (PELBART, 2000, p. 31).

$\mathrm{Na}$ busca de encontrar aliados para essas batalhas e criar novos agenciamentos que não se construam sob a lógica da semelhança, mas que se façam entre elementos heterogêneos, cada um a todos os outros, percebemos que algumas estratégias e experimentações que se inscrevem nessa trilha se fazem hoje no campo das artes ou estão a ele associadas. Não por coincidência. Entrar num processo de devir e deixar-se levar por ele, acompanhá-lo, está ligado ao um processo de singularização; implica seguir linhas de diferenciação portadoras de potências expressivas, entrar em um estado de experimentação, de exploração do meio, que é fundamental à criação artística. Por outro lado a possibilidade de criar formas e configurações a partir da sensibilidade de cada um e de seu processo é imprescindível para que se percorra esse trajeto sem desmoronar ou cair em expressões mortíferas do desejo.

Por outro lado, a associação ao campo estético e criativo pode ser acompanhada do desmanchamento ou do deslocamento da noção de invalidez, e trazer positividade a certas formas anômalas de existência. Talvez coisas que careçam de sentido mercantil e valor de mercado, como o sagrado, o lúdico, a loucura e a criação que está colocada fora do mercado da arte, possam ter lugar justamente para nos lembrar que a existência não se resume a motivações racionais ou 
produtivas nem à utilidade comercial ou mercadológica. Foucault já nos ensinava que ali onde incide o poder, no sujeito que não é senão efeito desse mesmo poder que produz, ali também se exerce a resistência. O sujeito - seja ele anormal, marginal, artista, terapeuta ocupacional - é produzido por um poder que determina para ele um lugar na estratificação social. Mas este mesmo sujeito pode também produzir-se, isto é, ele é potência de diferenciação, potência de subjetivação. É neste sentido que Foucault nos propõe o exercício poético de si na assunção da existência como obra de arte.

LIMA, E. M. F. A. About the desire for difference: considerations concerning the relation between occupational therapists and the population traditionally assisted by them. Rev. Ter. Ocup. Univ. São Paulo, v. 14, n. 2, p. 64-71, maio/ago. 2003.

\begin{abstract}
This paper is constructed based on the idea that the new direction of occupational therapy practices results from the occupational therapist's ethical and political commitment with the population assisted by this professional. In this sense, it proposes to think about this population, trying to create a transversal vision that goes from the population and excluding processes to the production of singularities and different ways of lives.
\end{abstract}

KEY WORDS: Occupational therapy/trends. Socialization. Social isolation.

\title{
REFERÊNCIAS
}

BASAGLIA, F. As instituições da violência. In: BASAGLIA, F. (Coord.) A instituição negada. Rio de Janeiro: Graal, 1985. p. 99-133.

BONNET, C. Introduction. In: BONNET, C.; LAZARUS, A.; DARCOURT, G. et al. Precarité et troubles psychiques, quelle politique? Pratiques en Santé Mentale: Rev Pratique de Psychol Vie Sociale et D'hygiène Mentale (Paris), n. 1, p. 1,2000 .

BRUNELlO, M. I. B.; CASTRO, E. D.; LIMA, E. A. Atividades humanas e terapia ocupacional. In: TERAPIA OCUPACIONAL NO BRASIL: fundamentos e perspectivas. São Paulo: Plexus Editora, 2001. p. 41-59

CARVALHO, E. A. Ética, solidariedade e complexidade. São Paulo: Palas Atenas, 1998. 77p.

CASTEL, R. Da indigência, à exclusão, à desfiliação. In: SAÚDE E LOUCURA 4. São Paulo: Hucitec, 1994. p. 21-48.

DELEUZE, G.; GUATTARI, F. Kafka: por uma literatura menor. Rio de Janeiro: Imago, 1977. 127p.

FOUCAULT, M. História da sexualidade I: a vontade de saber. Rio de Janeiro: Graal, 1982. 152p.

FOUCAULT, M. Os anormais. São Paulo: Martins Fontes, 2001. 479p.

GIL, J. Diferença e negação na poesia de Fernando Pessoa. Rio de Janeiro: Relume Dumará, 2000. 137p.
GUATTARI, F. Toward a new perspective on identity. In: GENOSKO, G. (Org.) The Guattari reader. Oxford: Blackwell, 1996. p.215-8.

GUATTARI, F.; ROLNIK, S. Micropolítica: cartografias do desejo. Petrópolis: Vozes, 1986. 327p.

LAZARUS, A. Les conséquences de la précarité du point de vue sociologique. In: BONNET, C.; LAZARUS, A.; DARCOURT, G. et al. Precarité et troubles psychiques, quelle politique? Pratiques en Santé Mantale: Rev Pratique de Psychol Vie Sociale et D'Hygiène Mentale (Paris), n. 1, p. 5-12, 2000 .

LAZZARATO, M. Luttes de minoritès et politique du dèsir. Rev. Chimères (Paris), n. 33, p. 53-62, 1998.

MACHADO, R., et. al. Danação da norma: medicina social e constituição da psiquiatria no Brasil. Rio de Janeiro: Graal, 1978. 559p.

NEGRI, A. Exílio. São Paulo: Iluminuras, 2001. 94p.

PAOLA, F. D. Soggetti diversi: singolaritá, psichiatria, neuroscienza. Milano: Libreria Dante \& Descartes, 1999. 85p.

PELBART. P. A vertigem por um fio. São Paulo: FAPESP / Iluminuras, 2000. 222p.

CURSO DE TERAPIA OCUPACIONAL DA FMUSP. Disponível em: http://www.usp.br/fm/to.

SOARES, L. B. Terapia ocupacional: lógica do capital ou do trabalho. São Paulo: Hucitec, 1991. 216p. 